\title{
METGES CANDIDATS A ACCIÓ CATALANA REPUBLICANA
}

\author{
CALBET i CAMARASA, Josep M.
}

Acadèmic corresponent de la Reial Acadèmia de Medicina de Catalunya.Barcelona (Barcelonès).jmcalbet@gmail.com

Rebut: 20 d'octubre de 2019

Acceptat: 29 d'octubre de 2019

\section{PARAULES CLAU:}

- Metges polítics

- Catalanisme polític

- Acció Catalana Republicana

- Diari "La Publicitat"

- Caricatures

\section{PALABRAS CLAVE:}

- Médicos políticos

- Catalanismo político

- Acció Catalana Republicana

- Diario "La Publicitat"

- Caricaturas

\section{KEYWORDS:}

- Politician doctors

- Political Catalanism

- Acció Catalana Republicana

- "La Publicitat" newspaper

- Caricatures
RESUM: Els metges formen part, en la mateixa proporció que diversos sectors socials, dels orígens del catalanisme polític i els trobem en esdeveniments del segle XIX com ara les Bases de Manresa. S'integren en els partits polítics, i alguns professionals, els anys vint del segle XX, a Acció Catalana. El diari "La Publicitat" publica la ressenya i caricatura dels que es presenten a les eleccions per Barcelona de 1931 per Acció Republicana.

RESUMEN: Los médicos forman parte, en la misma proporción que otros sectores sociales, de los orígenes del catalanismo político y los hallamos en los acontecimientos del siglo XIX como la Bases de Manresa. Se integran en los partidos políticos y algunos profesionales, en los años veinte del siglo XX, en Acció Catalana. El diario "La Publicidad" publica la reseña y la caricatura de los que se presentan a las elecciones por Barcelona de 1931 por Acció Republicana.

\section{ABSTRACT. PHYSICIAN CANDIDATES FOR THE PARTY "ACCIÓ} CATALANA REPUBLICANA": Doctors were part, in the same proportion as other social sectors, of the origins of political Catalanism and we find them in the events of the nineteenth century as the Bases of Manresa. They were integrated into political parties and some of them, in the twenties of the twentieth century in the party Acció Catalana Republicana. The newspaper "La Publicitat" publishes the profile and the caricatures of those standing for the elections for Barcelona in 1931 by the Acció Catalana Republicana.

CITACIÓ DE L'ARTICLE: CALBET i CAMARASA, Josep M. "Metges candidats a Acció Catalana Republicana". A: Gimbernat [Barcelona], 2020; 72: 141-146. http://doi.org/10.1344/gimbernat2020.72.9 


\section{INTRODUCCIÓ}

A les darreries del segle XIX I'Estat va ser dirigit per governs corruptes que estaven sota la protecció de l'exèrcit. Al mateix temps els catalans, malgrat la seva important contribució econòmica sofrien fortes pressions per a que renunciessin a la seva identitat. ${ }^{1}$ I fou en aquesta situació que es va reforçar un catalanisme polític que va procurar vertebrar l'economia i la identitat catalana, i que va tenir la seva projecció més important en l'assemblea coneguda com a Bases de Manresa (1892). ${ }^{2}$

A partir d'aleshores ja hi hauria un programa polític i econòmic per redreçar la nació catalana en totes les seves vessants. I els professionals de la sanitat, com a coneixedors més directes de les circumstàncies en què vivien els seus clients i de les seves aspiracions es van convertir, no solament en testimonis d'aquesta situació, sinó també en defensors d'un canvi que millorés la seva situació econòmica i política.

Però els avenços no van ser fàcils. Tot el poder de l'Estat es va posicionar en contra de la voluntat dels catalans. I això es plasmaria en diversos fets que registra la nostra història. Però al mateix temps, com a reacció, es van consolidar diversos partits polítics en defensa dels drets dels catalans.

El Centre Nacional Català des del 1899 generà una política anticentralista i junt amb la Unió Regionalista va demanar un pacte fiscal amb Madrid, cosa que I'Estat no podia ni volia concedir. Ben al contrari, la repressió contra les aspiracions catalanes es van endurir.

Però el 1901 sorgia la Lliga Regionalista que tingué un Ilarg i fructífer protagonisme en defensa de Catalunya. ${ }^{3}$

Amb aquests antecedents i amb tots els entrebancs difícils de superar, es va constituir el 1914 la Mancomunitat de Catalunya, que seria dirigida per Enric Prat de la Riba. Però la seva eficàcia política i econòmica va significar la seva dissolució.

En acabar la Primera Guerra Mundial sorgiren una sèrie de conflictes socials, que juntament amb l'ascendent solidesa que mostrava el moviment catalanista van provocar una duríssima reacció centralista que vingué representada per la Dictadura (1923-1930), i que va constituir un fre pel catalanisme. ${ }^{4}$ 
Però una creixent conflictivitat econòmica i social va donar ales a diversos partits, i entre ells Acció Catalana, ${ }^{5}$ que tenia com a portaveu el diari "La Publicitat", i tingué una notable influència. Les idees republicanes es van imposar lentament fins que el 1930 desapareix la Dictadura, i malgrat els esforços de reivindicar-la, van ser els elements republicans els que finalment es van imposar.

Era el 1931 quan Acció Republicana es va presentar a les eleccions a BarceIona, i entre els seus membres hi hem trobat cinc metges, que presentem en aquesta nota.

\section{LES CARICATURES PUBLICADES AL DIARI LA PUBLICITAT}

\section{Batlle de Miquelarena, Rafael}

Nascut a Sarrià (Barcelona) I'1 d'octubre de 1894, morí a Barcelona el 30 de desembre de 1985. Fill del metge Ramon Batlle i Prat. Batxiller a Barcelona el 1905 i llicenciat en medicina el 1911. Va ser el darrer alcalde de Sarrià (1918-1922) i posteriorment regidor de l'Ajuntament de Barcelona. Té un carrer amb el seu nom a la nostra capital.

\section{Mas i Oliver, Pere}

Nascut a Sant Feliu de Guíxols (Baix Empordà) el 24 de gener de 1895, morí a Barcelona el 2 de març de 1983. Fill del metge Joan Mas i Ministral. Batxiller a Girona el 1914 i llicenciat en medicina el 1921. Secretari de I'Institut Ginecos, que es va transformar en la Clínica Victòria. Membre fundador i president del Sindicat de Metges de Catalunya. Professor auxiliar de Medicina del Traball. El setembre de 1936 fou membre de la junta del Col-legi Oficial de Metges de Barcelona. Participà en la creació de la revista "Ars Medica".

\section{Nogués i Gurri, Lluís Gonçaga}

Nascut a Barcelona el 5 de febrer de 1885. Batxiller a Barcelona el $1900 \mathrm{i}$ llicenciat en medicina el 1908. El 1939 fou sancionat amb cinc anys d'inhabilitació. Consta la seva baixa col-legial el 6 de juny de $1941 .{ }^{7}$ 


\section{Santinyà i Bragulat, Joan B.}

Nascut a Barcelona el 4 de febrer de 1887, morí a Barcelona el 27 de gener de 1955. Batxiller a B. el 1902 i llicenciat en medicina el 1910. Presidí la secció de medicina de l'Associació General d'Estudiants de la Universitat de Barcelona. Membre fundador de la Societat Barcelonesa d'ORL (1911). Vicepresident de l'Institut MèdicoFarmacèutic. Participà en els Congressos de Metges de Llengua Catalana. Col·labora a la "Revista de Información Terapéutica", "Gaceta Médica Balear", i redactor de la "Revista Médico Sanitaria".

\section{Vivancos i Ferrés, Santiago}

Nascut a Sant Gervasi de Cassoles el 17 de maig de 1895 , morí a Barcelona el 21 de juny de 1939. Batxiller a Reus el 1915 i llicenciat en medicina el 1920. Doctorat a Madrid el 1929. També va fer estudis de Pedagogia a la Facultat de Filosofia i Lletres i les carreres de Dret i Farmàcia. ${ }^{8}$ El 1925 ingressà a la Mutual Salus. El 1926 era membre de la lògia “Justícia”, i més tard passà a la lògia “Themis" (1935), i va ser escollit com a Gran Maestre de la Gran Lògia de Catalunya el juliol de 1936. Membre d'Esquerra Republicana de Catalunya, simpatitzà amb Estat Català. En esclatar la guerra el 1936 dirigí la Mutualitat Catalana Mercantil i Industrial d'Accidents de Treball. El gener de 1938 era director del Sanatori d'infants "Àngel Guimerà". Professor a l'Escola de Treball. El novembre de 1936 era cap del Laboratori Químic de la secció d'espionatge de la Conselleria de Defensa. Quan passà el seu domicili a la Rambla de Catalunya, 114, principal, s'anuncia com especialista de malalties dels infants. ${ }^{9}$ Col·laborà a les revistes "Infantia Nostra", "Butlletí del Sindicat de metges de Catalunya", i "Revista Médico Professional". Fou detingut poques hores després d'haver entrat les tropes franquistes a Barcelona, i morí afusellat.

\section{NOTES}

1. OLLÉ ROMEU. Josep M. (dir.) Homes del catalanisme: Bases de Manresa, diccionari biogràfic. 1a ed. Barcelona: Rafael Dalmau editor, 1995. 285 p. (Camí Ral; 6), pàg. 11.

2. A les Bases de Manresa hi van assistir els metges: Domènec Agustí i Salmons, Jaume Baltasar i Matas, Ramon Enric Bassegoda i Amigó, Francesc de Paula Calbetó i Roget, Joan Capell i Solé, Jaume Ferran i Clua, Florentí Garcia i Fossas (també era farmacèutic), Agustí Maria Gibert i Oliver, Jaume Lacoma i Aliá, Jacint Laporta i Mercader, Salvador 
Massa i Passapera, Francesc Miravet i Garcés, Oleguer Miró i Borràs, Feliu Noguera Casabosch, Pere Poblet i Andreu, Miquel Pons i Riera, Enric Octavi Raduà i Oriol, Josep Reventós i Amiguet, Josep Narcís Roca i Farreras, Joan Sala i Papell, Pere Sala i Vendrell, Josep Saltor Montagut, Frederic Serra i Crehuet, Marià Serra i Font, Cels Surroca i Salvador, i Pere Vergés i Vernís. I els farmacèutics: Antoni Anyon i Cortiella, Josep Corominas i Font, Miquel Draper i Batllori, Gaietà Florensa i Jové, Martí Genís i Aguilar, Bonaventura Gombau i Lleonart, Antoni Lamich i Governa, Josep M. Martí i Terrada, Marià Pedrol i Balart, Tomàs Raguer i Fossas, Jaume Soler i Farré, i Josep M. Valeta i Castelló.

3. En la Lliga Regionalista hi van destacar els metges Bartomeu Robert i Yarzábal, i Miquel Arcàngel Fargas i Roca.

4. La cara amable de la Dictadura es va voler demostrar amb la inauguració del monument a Jacint Verdaguer a Barcelona amb la presència del Rei i del general Primo de Rivera, el qual va llegir una poesia en català del poeta.

5. Posteriorment contribuí a crear Esquerra Republicana de Catalunya.

6. La Publicitat [Barcelona], (12 febrer 1931), p. 6.

7. Informació verbal facilitada per Mercè Viger.

8. El Diluvio [Barcelona], (2 juny 1929), p. 30.

9. La Publicitat [Barcelona], (18 agost 1931), p. 5.

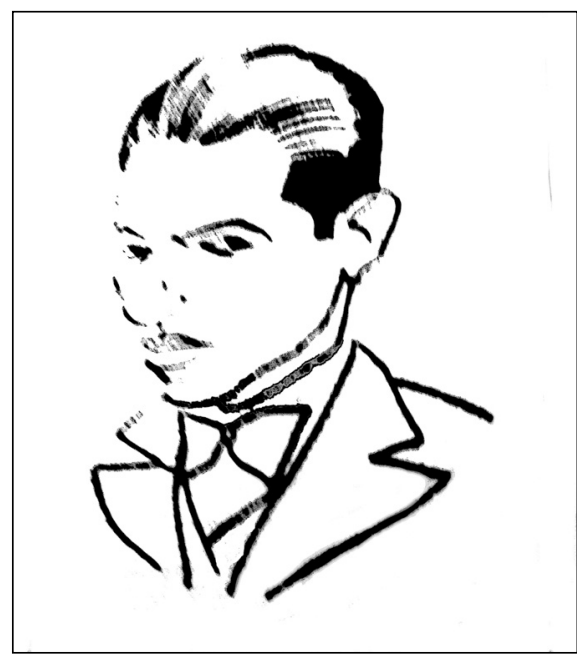

1

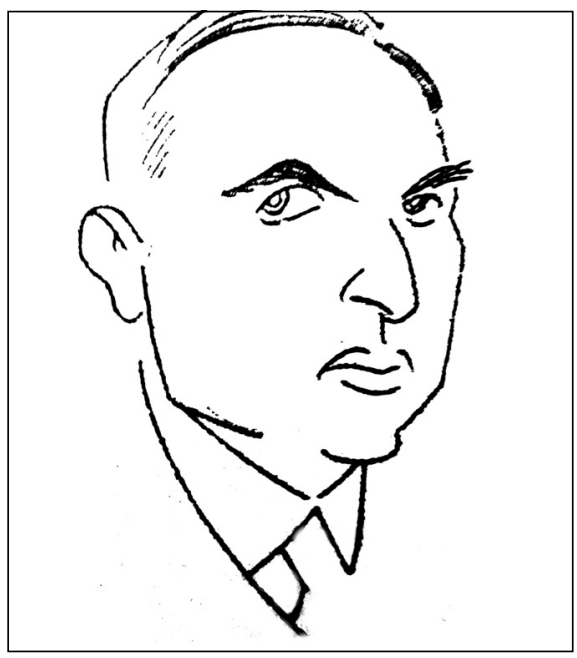

2

Figura 1. Rafael Batlle de Miquelarena.

Figura 2. Pere Mas i Oliver. 

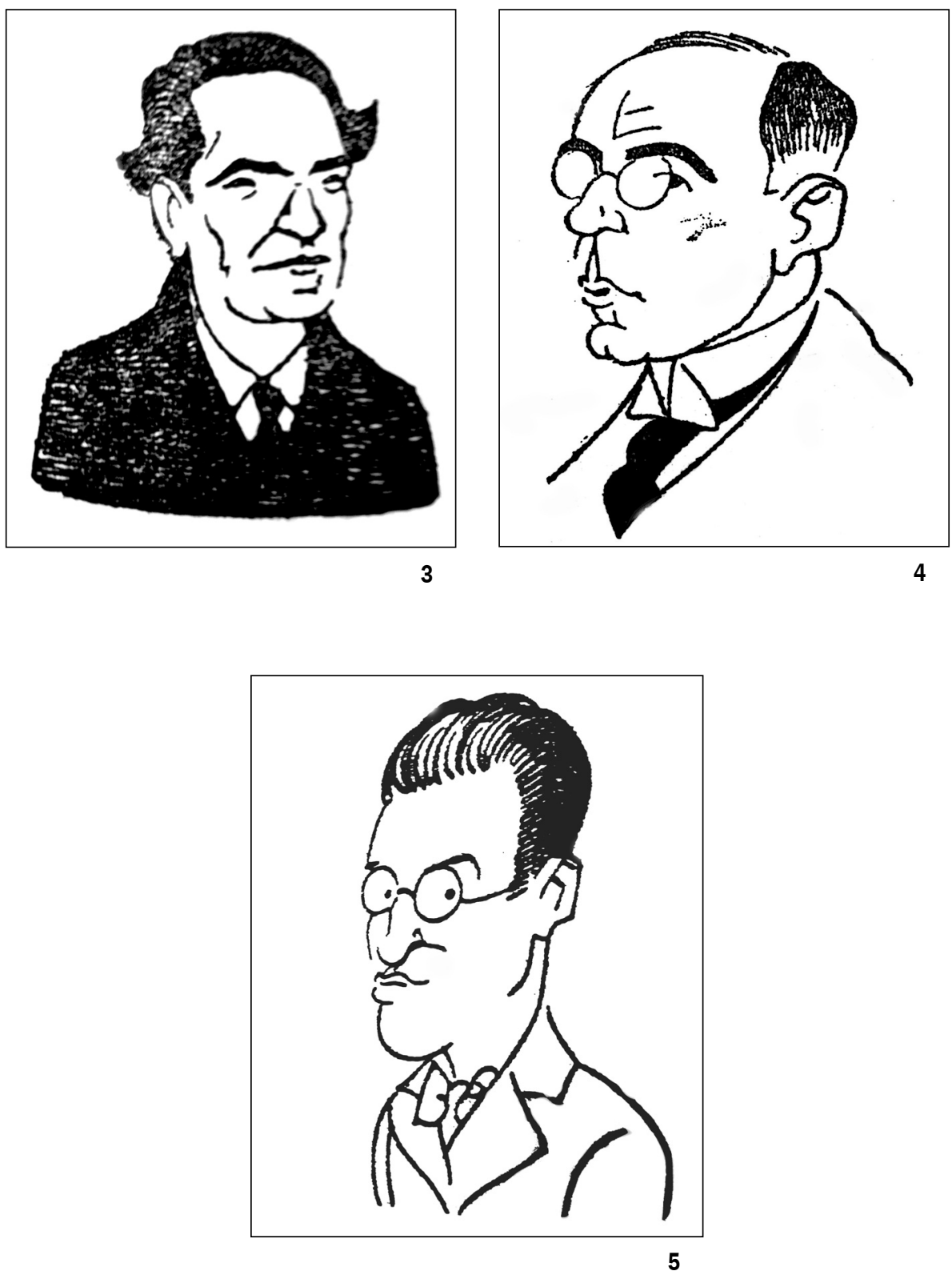

Figura 3. Lluís Gonçaga Nogués i Gurri.

Figura 4. Joan B. Santinyà i Bragulat.

Figura 5. Santiago Vivancos i Ferrés. 